CORRESPONDENCE

\section{Determining collateral ventilation during bronchoscopy: unanswered questions}

In their recent review, Shah et al ${ }^{1}$ made an excellent presentation of the latest perspectives of lung volume reduction with endobronchial valves, emphasising the importance of collateral ventilation (CV) and fissure analysis on selecting proper candidates, as shown in the VENT studies. $^{2}{ }^{3}$ The authors described representative cases of patients with positive and negative $\mathrm{CV}$ using the Chartis system ${ }^{4}$ and recommended that persistence of flow after $5 \mathrm{~min}$ of balloon inflation, particularly where more than a litre of air has been expelled, suggests the presence of significant $\mathrm{CV}$.

Our centre has extensive experience in evaluating CV with Chartis. We agree with Dr Shah and colleagues on their clear definition of positive CV. We feel, however, that the accurate assessment of negative $\mathrm{CV}$ is not always straightforward. Over the last few years, we have frequently witnessed what we refer to as the 'collapse' or 'low-flow' phenomenon, which is attributed to the dynamic collapse of the airways observed especially in the lower lobes in emphysema patients. It usually occurs directly after balloon inflation and valve activation and is characterised by a sudden stop of flow and increase in airway resistance index to infinity during only a few breathing cycles (figure 1A). When assessing the left upper lobe in the same patient (figure 1B), a good flow signal with a steep downward trend can be observed, resulting in no flow only $1 \mathrm{~min}$ after valve activation, with the total exhaled volume being less than $30 \mathrm{~mL}$. This effect may also be related to delayed airway collapse rather than true absence of CV. Furthermore, we have occasionally witnessed borderline measurements, which are more difficult to assess whether they can be attributed to the absence of CV or a somewhat prolonged collapse phenomenon (figure 1C).

Although the difference between positive and negative $\mathrm{CV}$ appears to be quite clear, the cut-off between a negative measurement and a collapse phenomenon is still very ill-defined. Clearly, there is a need to define a threshold with respect to the time of evaluation and the amount of total exhaled volume, below which

A.
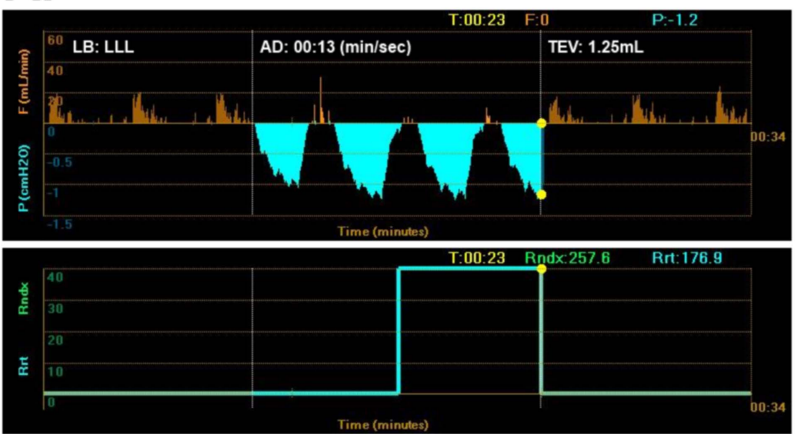

B.
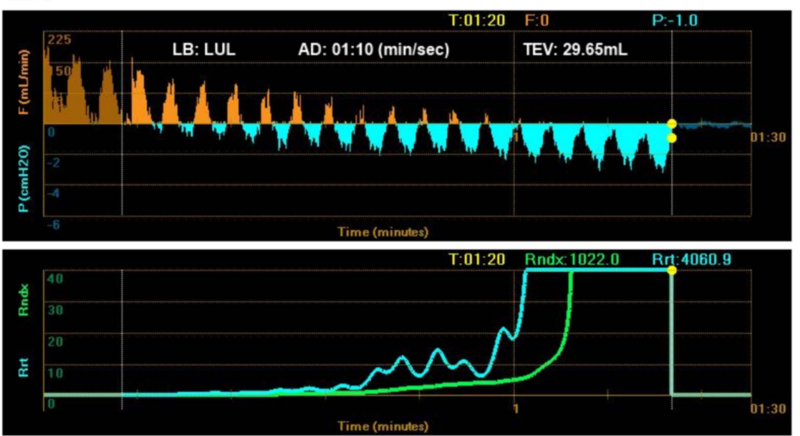

C.

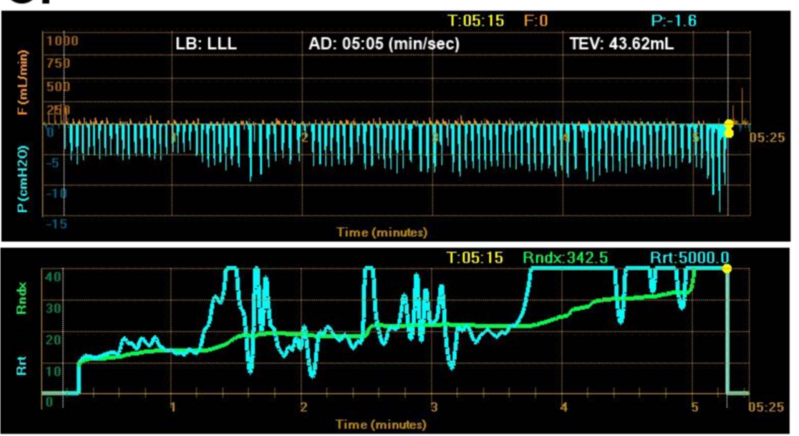

Figure 1 (A) Chartis output while assessing collateral ventilation in the left lower lobe of a patient with emphysema, representative of a 'collapse' phenomenon: a sudden stop of flow and increase in airway resistance index to infinity directly after valve activation. (B) Chartis output in the same patient while assessing the left upper lobe, demonstrating initially a good expiratory flow signal that gradually decreases and quickly reaches zero in only 1 min while the total exhaled volume is less than $30 \mathrm{~mL}$, an effect that could also be related to airway collapse distal to the inflated balloon. (C) A rather more ambiguous Chartis measurement displaying low but continuous flow that diminishes after $5 \mathrm{~min}$ at which point the resistance index rises to infinite, but the total exhaled volume is only $43 \mathrm{~mL}$. LB, lobe; LLL, left lower lobe; LUL, left upper lobe; $A D$, assessment duration; TEV, total exhaled volume; $F$, flow; $P$, pressure; Rndx, resistance index, Rrt, resistance.

measurements should be attributed to a collapse phenomenon. In our experience, reproducible measurements that account for less than $1 \mathrm{~min}$ in duration and/or less than $50 \mathrm{~mL}$ of total volume should not be considered as a CV negative result. In such cases, neighbouring lobe measurements and fissure analysis should be performed. Moreover, future studies should also evaluate the prognostic importance of this 'collapse' phenomenon on the clinical outcomes of endobronchial valve placement, as treatment alternatives increasingly emerge for these patients.

Wolfgang Gesierich, ${ }^{1}$ Konstantinos Samitas, ${ }^{1,2}$ Juergen Behr ${ }^{1}$

${ }^{1}$ Klinik für Pneumologie, Asklepios Fachkliniken München-Gauting, Comprehensive Pneumology Center, Gauting, Germany

${ }^{2} 7$ th Respiratory Department and Asthma Centre Athens Chest Hospital "Sotiria", Athens, Greece

Correspondence to Dr Wolfgang Gesierich, Asklepios Fachkliniken München Gauting, Comprehensive Pneumology Center, Robert-Koch-Allee 2, Gauting D-82131, Germany; w.gesierich@asklepios.com 
Contributors WG, KS and JB conceived the idea. WG and KS drafted the first version of the manuscript. KS prepared figure graphics. JB revised the manuscript and made substantial intellectual contributions. All authors approved the final version of the manuscript. WG is responsible for the overall content as guarantor.

Competing interests None.

Patient consent Obtained.

Provenance and peer review Not commissioned; externally peer reviewed.

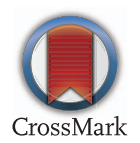

To cite Gesierich W, Samitas K, Behr J. Thorax 2014;69:289-290.

Received 25 October 2013

Accepted 23 November 2013

Published Online First 16 December 2013

\section{CLinked}

http://dx.doi.org/10.1136/thoraxinl-2013-203743

- http://dx.doi.org/10.1136/thoraxjnl-2013-204875

Thorax 2014:69:289-290.

doi:10.1136/thoraxjnl-2013-204749

\section{REFERENCES}

1 Shah PL, Herth FJ. Current status of bronchoscopic lung volume reduction with endobronchial valves. Thorax 2014;69:280-6.

2 Herth FJ, Noppen M, Valipour A, et al. Efficacy predictors of lung volume reduction with Zephyr valves in a European cohort. Eur Respir J 2012;39:1334-42.
3 Sciurba FC, Ernst A, Herth FJ, et al. A randomized study of endobronchial valves for advanced emphysema. N Engl J Med 2010;363:1233-44.

4 Herth FJ, Eberhardt R, Gompelmann D, et al. Radiological and clinical outcomes of using Chartis to plan endobronchial valve treatment. Eur Respir J 2013:41:302-8 